\title{
Severe dengue in travellers: pathogenesis, risk and clinical management
}

Scott Halstead ${ }^{1}$, Annelies Wilder-Smith ${ }^{2,3}$

1 Emeritus Professor, Uniformed Services University of the Health Sciences, Bethesda, MD USA

2 Department of Disease Control, London School of Hygiene and Tropical Medicine, UK

3 Heidelberg Institute of Global Health, University of Heidelberg, Germany

Corresponding author: Annelies Wilder-Smith: nnelies.wilder-smith@1shtm.ac.uk

\begin{abstract}
:
Rationale for review: Dengue is a frequent cause of febrile illness among travellers and has overtaken malaria as the leading cause of febrile illness for those traveling to South East Asia. The purpose is to review the risk of dengue and severe dengue in travellers with a particular focus on the pathogenesis and clinical management of severe dengue.

Risk, pathogenesis and clinical management: The risk of travel-acquired dengue depends on destination, season and duration of travel and activities during travel. Seroconversion rates reported in travellers therefore vary between less than $1 \%$ to more than $20 \%$. The most common lifethreatening clinical response to dengue infection is the dengue vascular permeability syndrome, epidemiologically linked to secondary infection, but can also occur in primary infection. Tertiary and quaternary infections are usually associated with mild or no disease. Antibody-dependent enhancement, viral factors, age, host factors, and clinical experience of the managing physician modulate the risk of progressing to severe dengue. The reported relative risk of severe dengue in secondary versus tertiary infection ranges from 2 to 7 . The absolute risk of severe dengue in highly endemic areas in children is about $0.1 \%$ per year for primary infections, and $0.4 \%$ for secondary infections. About $2-4 \%$ of secondary infections
\end{abstract}


lead to severe dengue. Severe dengue and death are both relatively rare in general travellers, but more frequently in those visiting friends and relatives (VFR). Clinical management of severe dengue depends on judicious use of fluid rehydration.

Conclusions: Although dengue is a frequent cause of travel illness, severe dengue and deaths are rare. Nevertheless, dengue infections can interrupt travel, lead to evacuation and major out-of-pocket costs. Dengue is more frequent than many other travel-related vaccine preventable diseases such as hepatitis A, hepatitis B, rabies, Japanese encephalitis, and yellow fever, indicating a need for a dengue vaccine for travellers.

Key words: antibody-dependent enhancement, capillary leakage, dengue haemorrhagic fever, dengue vaccines, CYD-TDV, Aedes, risk assessment

\section{Introduction and objectives}

During the past 50 years, dengue viruses have emerged from an endemic focus in Southeast Asia to a global pandemic. ${ }^{1}$ Dengue infections are increasing at higher rates than any other communicable disease, with a 400\% increase over 13 years (2000-2013) according to the Global Disease Burden study. ${ }^{2}$ Although still regarded a neglected tropical disease, investments in vaccine development and novel vector control measures have increased exponentially in the past decade. ${ }^{3}$ The four mosquito-borne dengue viruses are now endemic in urban and rural areas in more than 100 tropical and subtropical countries with annually 50- 100 million estimated cases. ${ }^{4}$ Many dengue endemic countries are well-known travel destinations with cultural or recreational features that attract visitors from around the world. Dengue is hence a frequent cause of febrile illness among travellers returning from Southeast Asia, Latin America or the Caribbean, ${ }^{5,6}$ and has overtaken malaria as the leading cause of febrile illness for those traveling to South East Asia. ${ }^{7}$ A tripling of hospitalization for dengue in US travellers was reported between 2000-2007. ${ }^{8}$ There has been a corresponding increase in dengue reported in European travellers. ${ }^{9,10}$ Dengue can occur in tourist travellers, business travellers, migrants and those visiting friends and relatives (VFR), South-South travellers, and pilgrims ${ }^{11-16}$; both in adult ${ }^{7,17}$ and pediatric travellers. ${ }^{18,19}$ 
Air travel between dengue-endemic countries and from dengue-endemic countries to non-endemic has increased exponentially, thus, travellers contribute to the global spread of dengue. ${ }^{20-25}$ About $36 \%$ of travellers who acquired dengue during travel to dengue endemic countries returned to Europe during the acute phase of the infection (up to 7 days after symptom onset), and 58\% of travellers with an acute dengue infection were viraemic when seeking medical care, highlighting the risk of autochthonous infection if returning to areas where Aedes mosquitoes are present. ${ }^{26}$ Returning viraemic travellers may initiate local transmission although recent modeling estimated the potential for dengue establishment in Europe to be very low. ${ }^{27}$ Travellers also serve as sentinels to identify silent dengue transmission in particular in countries or continents that may underreport dengue such as Africa. ${ }^{28}$

The incubation time of dengue is 7-10 days. Dengue is usually a self-limited acute febrile disease; however, hospitalization for dengue in travellers is fairly common ${ }^{6}$ and dengue illness can disrupt travel resulting in evacuations back home. ${ }^{29}$ In a study on travel-associated dengue, $22 \%$ reported hospitalization and 32\% receiving ambulatory care whilst travelling, these percentages were higher at $39 \%$ and $71 \%$, respectively, after returning home..$^{30}$ The out-of-pocket direct and indirect costs of dengue illness were US\$421 and US\$571 per episode, respectively, averaging to a total out-of-pocket cost of US\$992 per episode, suggesting that international travellers incur important direct and indirect costs because of dengue-related illness.

When dengue illnesses are seen by health care workers unfamiliar with diagnostic features, misdiagnosis may delay treatment or result in mismanagement with increased risk of severe dengue with complications or death. The purpose is to review the risk of dengue in travellers and the travel medicine practice implications thereof. A particular focus of this review is the pathogenesis and clinical management of severe dengue in travellers.

\section{Background}

\section{(1) Dengue viruses and its vectors}

Human dengue infections are caused by any of the four dengue viruses, types 1, 2, 3 and 4 . These are transmitted in a cycle from viraemic to susceptible hosts principally by Aedes aegypti mosquitoes, a species that has been immensely successful in surviving in human environments. The mosquito breeds in a huge variety of containers,large and small, throughout the tropical and subtropical world. A secondary vector, Aedes 
albopictus has recently spread from Asia to tropical, subtropical and temperate countries around the world. ${ }^{31}$ Sexual transmission of dengue virus as seen for Zika virus has not been shown for dengue, except for one probable instance. ${ }^{32,33}$

\section{(2) Pathogenesis of dengue and severe dengue}

Four immunologically distinct but ecologically and biologically identical dengue viruses often circulate in the same area. The pathophysiological responses to infections with the four dengue viruses in hosts differing in immune status make dengue a highly complex disease. Central to dengue pathogenesis is the ability of dengue viruses to target cells of mononuclear cell lineage. ${ }^{34} 35$ IgG antibodies residual from first infections form infectious immune complexes with a second infecting (different) dengue virus. These complexes attach to Fc receptors sending signals that partially cripple innate antiviral responses resulting in intrinsic antibody dependent enhanced infection (ADE). This may produce a hundred to thousand-fold increase in production of dengue virions in each infected cell. ${ }^{36-39}$ Severe dengue disease accompanies second heterotypic dengue infections that occur no less than 2 - 3 years apart in at least 12 different sequences (e.g, DENV 1 followed by DENV 2 , DENV 3 then 4, etc.). Unique in human medicine, dengue IgG placental antibodies from mothers with two or more lifetime dengue infections degrade from protective concentrations at birth to dengue disease enhancing concentrations several months later. ${ }^{40}$ In highly endemic SE Asian countries, severe dengue in infants comprise $5 \%$ of total hospitalizations of children. ${ }^{41}$

The most common life-threatening clinical response to dengue infection is the dengue vascular permeability syndrome (DVPS). This is a febrile dengue infection that evolves to include a) Thrombocytopenia (b) Altered hemostasis: most commonly prolonged bleeding time and/or elevated aPTT (activated partial thromboplastin time) and/or elevated prothrombin time (c) Activated complement, by classical and alternative pathways (d) Elevated liver transaminase enzymes, and (e) Vascular permeability. ${ }^{42}$ Significant fluid volume and small macromolecules (e.g., albumin) are lost from the circulation into interstitial spaces and commonly into serosal spaces. This fluid loss may occur rapidly and often starts 3 or more days after onset of fever. During much of the early history of DVPS fluid loss from circulation was inferred from hematocrit values. ${ }^{43,44}$ Today, ultrasound examination can detect fluid loss rapidly and sensitively. ${ }^{45,46}$ Peak vascular permeability accompanied by profound vascular instability usually accompanies defervescence. ${ }^{44,47}$

Antibody-dependent enhancement (ADE) was postulated to be the pathophysiological mechanism triggering DVPS in the 1970`s, based on in-vitro studies. ${ }^{48}$ Recent discoveries with regards to dengue non-structural protein 1 (NS1) have added a disease inducing mechanism to a 
kinetic phenomenon (ADE). Dengue NS1 that circulates in the blood throughout infection at high concentrations has direct toxic properties making dengue shock syndrome a viral analog of bacterial toxic shock syndrome. ${ }^{49,50}$ DENV NS1 can produce endothelial hyperpermeability in vitro and vascular leak in vivo. In a mouse model circulating NS1 alone leads to vascular permeability, accompanied but not preceded by circulating levels of inflammatory cytokines. ${ }^{51}$ Meanwhile, a mystery prevails in understanding the pathophysiology. While in animal models, endothelial cells are rapidly damaged by DENV NS1, in humans, severe vascular permeability is a rare event. ${ }^{52}$ Furthermore, vascular leakage is temporally linked to defervescence, a time when circulating levels of NS1 are low. Defervescence in viral diseases usually signals the termination of intracellular infection by cell-mediated immunity. Only a small fraction of secondary infections lead to severe disease. One reason may be a requirement for a low level of circulating dengue antibodies. Prospective cohort studies have shown that children who had severe secondary infections had baseline pre-infection antibodies within a certain titer range. ${ }^{53,54}$

Besides ADE, viral factors play a role with some serotypes and genotypes expressing higher rates of overt dengue disease outcomes than others. ${ }^{55}$ Amino acid substitutions that change the subtype or clade within a genotype can influence transmission dynamics. The DENV-2 epidemic in Cuba in 1997 was attributed to a single amino acid substitution in the NS1 protein compared to the DENV-2 that had been present on the island prior to the epidemic. ${ }^{56}$ Dengue virus serotype 2 is also more often associated with severe dengue than other serotypes. ${ }^{57}$ Age-related differences in microvascular permeability are also significant factors making infants more susceptible to dengue shock. ${ }^{58}$ Genetic host factors are also important: a genome-wide association study identified susceptibility loci for dengue shock syndrome at two loci. ${ }^{59}$ Host factors also contribute to clinical outcome of DENV infections genes in the lipid and steroid metabolism pathways. ${ }^{59}$ Polymorphisms in the genes that encode proteins that function in pathways that link lipid metabolism with immune response may explain the reduced susceptibility of the black race to severe dengue. ${ }^{60}$ However, the broad background flavivirus exposure observed frequently in Africa may result in cross-protection contributing to less severe dengue disease in Africa. More research is needed with regards to the influence of race.

Preexisting high antibody titers to dengue virus were associated with reduced risk of ZIKV infection and symptoms. ${ }^{61}$ The 2015 -2016 Zika epidemic in the American tropics resulted in an approximately 80\% reduction in reported dengue cases in 2017-18. ${ }^{62}$ More research is needed to address the possible immunological mechanisms of cross-protection between ZIKV and DENV and whether DENV immunity also modulates other ZIKV infection outcomes such as neurological or congenital syndromes ${ }^{63}$, but preliminary data suggests that a previous DENV infection partially protects against congenital Zika syndrome. ${ }^{64}$ 


\section{Risk of dengue in travellers}

About 128 countries are potential travel destinations where dengue virus is circulating. ${ }^{65}$ GeoSentinel is a global network of travel medicine providers who attend to returning travellers ${ }^{66}$ : GeoSentinel has documented an increase of dengue in returning travellers over the past decades. ${ }^{67,68}$ In Southeast Asia, annual proportionate morbidity increased from 50 dengue cases per 1,000 ill returned travellers in non-epidemic years to an average of 159 cases per 1,000 travellers during epidemic years. ${ }^{7}$ The intensity of dengue transmission is influenced by locale within dengue endemic countries, population density, social, economic, cultural, demographic and ecological factors such as temperature, season, rainfall and altitude. Accordingly, the risk of dengue infection varies widely between and within countries, and also from year to year, and season to season, as shown in a GeoSentinel analysis. ${ }^{7}$ In addition, the risk of dengue for travellers depends not just on these large-scale risk factors but upon specific activities in each dengue endemic destination.

US travellers from the Boston Area Travel Medicine Network traveling to dengue endemic countries with a median length of travel of 21 days had a seroconverson rate by either anti-DENV IgM or IgG ELISA between 2.9 and $6.8 \% .{ }^{69}$ In this study, the ratio of asymptomatic to symptomatic dengue was about 4 to 1 . This asymptomatic to symptomatic ratio was also documented in another study: $85 \%$ travellers with lab-confirmed dengue infections had no history of dengue. ${ }^{70}$ For US travellers, the largest number of travel-acquired dengue infections occurred as a result of travel to the Caribbean, Mexico and Central America, followed by Asia. ${ }^{71}$ For travellers returning to Europe, South-East Asia was the most important destination for dengue acquisition, followed by Latin America, the Indian subcontinent, the Caribbean, and Africa. ${ }^{72}$ In GeoSentinel, which presents a more global picture, overall dengue cases varied monthly between Southeast Asia (June, September), South Central Asia (October), South America (March), and the Caribbean (August, October). ${ }^{7}$

In most travellers` studies the attack rate of dengue cannot be determined due to the lack of a denominator. In Sweden, data both for legally notifiable dengue cases and travel volumes are available, making it possible to study attack rates. An increasing trend of symptomatic dengue infections for most tropical destinations among Swedish travellers. ${ }^{9}$ The attack rate was 13.6 (95\% CI 12.7, 14.4) to Thailand, 45 for Sri Lanka and 43 for per 100,000 travellers. Table 1 summarizes the attack rates from different studies in travellers. 


\section{Sub-populations of travellers:}

Business travellers: Given that dengue is predominantly a disease of urbanized areas ${ }^{73}$, even short-term travel for business in cities poses risk. Expatriates in Delhi, India, were shown to be at higher risk for dengue than the endemic population. ${ }^{74}$

Long-term travellers and persons with prolonged residence in dengue endemic countries (expats): The prevalence of positive dengue ELISA in travellers from non-endemic countries to dengue-endemic countries for more than 2 weeks but less than 1 year was $7 \%$; for those who traveled for more than one year, it was $40 \%{ }^{70}$ The incidence of clinically apparent infections with laboratory-confirmation by a positive NS1 antigen test in Peace Corps Volunteers was 1.12 cases per 1000 volunteer-months, with the highest rate reported in the Caribbean region, with a rate of 5.51 cases per 1000 volunteer-months followed by the East Asia/South Asia region (3.34) and Central America (2.55). ${ }^{75}$ In pre-deployment and postdeployment sera collected from US Army Special Operations Forces deployed to South and Central America, Africa, and Southeast Asia, the seroconversion rate was $13 \%{ }^{76}$

Migrants: Despite increasing migration, including South-South migration ${ }^{77,78}$, little is known about the incidence of dengue in migrants. In migrants now living in non-endemic countries returning to dengue endemic countries to visit friends and relatives (VFR), a higher risk of severe dengue compared to tourist travellers was documented in a GeoSentinel study ${ }^{79}$, which was most likely due to the fact that many of the VFRs already had a primary dengue infection and were hence at a higher risk of more severe dengue during their second infection. Dengue was shown to have increased in Colombia as a result of migration from Venezuela ${ }^{80}$, but no data exist on the incidence of dengue in migrants.

Paediatric travellers: Although dengue is primarily seen in children and adolescents in dengue endemic countries, dengue in paediatric travellers is rarely reported, most likely because the majority of travellers are adults. A primary infection in children is more likely to be mild or asymptomatic; however, secondary infections in children in endemic countries dispose more often to dengue shock, whilst in adults, internal bleeding is more frequent. ${ }^{81}$ The death rate for children aged 3-14 years was 14.5-fold higher than in young adults aged 15-39 years. The death rate rose somewhat in adults aged 50 years and older; hospitalizations due to dengue haemorrhagic fever showed the same trend as death rates. ${ }^{82}$ One unusual case in a 8 year old traveller with severe dengue who presented with a nephrotic-range proteinuria. ${ }^{83}$ Children VFR may be at higher risk for severe dengue, similarly to adult VFR, due to second infection. ${ }^{84}$ 
Older travellers: Many travellers are older adults, and older travellers usually exhibit more co-morbidities. Diabetes has been identified as a risk factor during primary or secondary dengue infections for a more severe clinical course, and so have other co-morbidities such as hypertension, cardovascular disease and asthma. ${ }^{85,86}$ Dengue can result in diverse cardiac manifestations including myocardial dysfunction and a broad range of rhythm disturbances. ${ }^{87}$

Travellers on anti-coagulants: Patients on anti-coagulants pose particular challenges; no guidelines exist when to stop and re-start anti-coagulant therapy during the critical phases of dengue with thrombocytopenia and bleeding tendencies.

Pregnant travellers: Pregnant women are at higher risk for severe disease, especially during the third trimester. ${ }^{88,89}$ Two large epidemiological studies from Brazil indicate that symptomatic dengue during pregnancy is associated with an increased risk of preterm birth and fetal death though not with congenital malformations. ${ }^{90,91}$ Perinatal transmission to infants is recognised. ${ }^{92}$ Vertical transmission is common among mothers who are viraemic at delivery. ${ }^{93}$ But transplacental transmission is not thought to occur during infections that occur earlier during gestation, but formal data are lacking. Dengue virus was retrieved from $75 \%$ of 12 infected breastfeeding mothers, so transmission via breastfeeding is plausible although no cases have been reported. ${ }^{93}$

Travellers with sickle cell disease: Persons with sickle cell disease are thought to be at increased risk of severe dengue, although the strength of the evidence is limited due to the scarcity of data in this population. ${ }^{94}$

\section{Severe dengue in travellers}

Travel medicine providers need to be aware of the complexities of risk assessments in travellers. ${ }^{95}$ The absolute annual risk of severe dengue depends on many factors which include the transmission intensity in the destination country, the time interval to the preceding dengue infection, seasons and epidemic years, host and genetic factors, other flavivirus exposure, expertise in clinical management, and age. Severe dengue is overall a rare event, and therefore large prospective studies involving ten thousands of travellers are required in diverse geographic settings to determne the true risk of severe dengue in travellers. Such large studies do not exist for travellers. In the endemic population, many lessons can be gleaned from the Phase 3 trials by Sanofi Pasteur in 10 highly dengue endemic countries where 30,000 children were followed up for 6 years. The 
placebo arm involved about 10,000 children aged 2 to 16, recruited in sites chosen for their high dengue transmission intensity. The risk for severe dengue was higher in younger children (ages 2-8 versus 9-16), and depended on serostatus: The absolute annual risk for severe dengue in dengue (Table 2). Such data cannot be extrapolated to travellers, as the duration of exposure is usually not a year, and there are differences in host, age, and background flavivirus exposure.

Results from most published studies in travellers are based on passive surveillance, or referral centers, or sentinel surveillance, and hence the denominator is different, or even absent. Here we present some published data; none of them are prospective cohort studies: Of 219 imported dengue virus cases seen in 14 European centres, $17 \%$ had a secondary dengue infection. ${ }^{96} 17$ out of these 219 had any spontaneous hemorrhage, the majority of which were mild such as epistaxis or gum bleeding, and none required blood or platelet transfusions. In addition, only 2 patients met the WHO criteria for DHF, and none had dengue shock syndrome (DSS). Nevertheless, altogether 23 (11\%) travellers had significant clinical manifestations (internal hemorrhage, plasma leakage, or marked thrombocytopenia) even if not fulfilling the criteria for DHF at the time. A secondary immune response was significantly associated with both spontaneous bleeding and other severe clinical manifestations. In another study in US travellers, of 334 laboratory confirmed dengue infections, $12 \%$ were hospitalized and 2 died (1\%). ${ }^{71}$ No deaths were described in a cohort of 242 acute dengue infections imported to Europe by returning travellers from 2012 to $2014 .{ }^{26}$ In 35 Israeli travellers hospitalized for laboratory confirmed dengue, 12 (34\%) patients had sonographic signs of sub-clinical capillary leakage, which was found in 32\% of primary dengue cases and in $40 \%$ of secondary dengue cases. ${ }^{97}$ However, as highlighted further below, sub-clinical fluid accumulation around the gallbladder, thickening of the gallbladder, or minor perihepatic fluid accumulation are not signs of nor reliably predictive of progression to severe dengue. Two patients with primary dengue infection presented as dengue haemorrhagic fever, underlining again that primary infections can also have severe manifestations.

In a modelling study by Stanaway et al, the case fatality rate due to dengue was higher in the US compared to dengue endemic countries in Asia or Latin America. ${ }^{98,99}$ This could be a modelling artefact, or reflect the possibility that Western physicians are not familiar with the management of severe dengue. For example, a A female traveler was hospitalized with fever and abdominal pain after returning from Ecuador. Due to a suspected acute acalculous cholecystitis, cholecystectomy was performed. After cholecystectomy, severe spontaneous bleeding from the abdominal wound occurred and the patient died. Postmortem analysis of transudate and tissue demonstrated a DENV secondary infection and a gallbladder wall 
thickening due to an extensive edema. ${ }^{100}$ This was an avoidable death if the physicians had recognized the diagnosis and understood the clinical course of dengue. Fortunately, overall, dengue deaths are rare. One death in a Norwegian traveller was due to a subarachnoidal haemorrhage related to thrombocytopenia, without otherwise criteria for dengue haemorrhagic fever. ${ }^{101}$ A traveller returning to the Netherlands presented with dengue-related encephalopathy. This patient had a primary dengue infection who, in the absence of overt signs of dengue shock syndrome, died due to progressive cerebral oedema. Autopsy findings demonstrated loss of integrity of cerebral vascular endothelium and involvement of complement activation. ${ }^{102}$ Among 82,825 ill Western travelers reported to GeoSentinel, one death was recorded due to severe dengue. ${ }^{103}$ In summary, dengue related deaths in travellers have been reported sporadically, were usually associated with secondary infections, but deaths have also occurred after primary infections.

\section{What is the risk of severe dengue following a secondary infection?}

This is a frequently asked question by travellers and travel medicine providers alike. Amongst the lay public and health professionals there is great concern and fear for travellers with a laboratory confirmed dengue infection from previous travel that a second infection would place such travellers at immense risk of severe dengue. It is an important question because it may have practical consequences including decisions to forego any repeat travel to dengue endemic countries and areas. Given that more than 128 countries are now dengue endemic, this would be a massive restriction on hundreds of thousands of travellers even not millions. There are also legal and litigation implications for employers or the military for deploying staff or military after a primary dengue infection to countries where such persons may be at risk of a secondary infection. ${ }^{104}$ As outlined above, given the absence of large prospective studies in travellers, we do not have an evidence base for providing appropriate risk assessments and counselling. Therefore we need to glean from epidemiological studies in endemic populations, and also on our pathophysiological understanding of severe dengue.

Following a primary infection with one dengue virus serotype, protection against the infecting serotype (homotypic protection) is considered to be life long, while temporary cross-protection is induced to infection and/or disease accompanying infection with another serotype (heterotypic protection). The ADE phenomenon suggests that quantitative virus-infected cells determine disease severity. Accordingly, severe dengue can accompany first as well as secondary dengue infections. Both the risk and severity of secondary infections are higher than that of first dengue

infections, as shown in various epidemiological studies. ${ }^{105-108}$ Recent modelling studies have provided better estimated for the incidence of 
symptomatic dengue versus asymptomatic in primary versus secondary dengue infections: the proportion of infections that are symptomatic for first infections as 0.18 (95\% Credible Interval, CI: $0.16,0.20), 0.13$ (95\% CI: $0.05,0.17)$ for individuals infected in the year following a first infection and 0.41 (95\% CI: $0.36,0.45)$ for those experiencing secondary infections after this first year. ${ }^{109}$

The ratio of symptomatic versus inapparent outcomes in repeat dengue virus infections is influenced by the time interval between infections. ${ }^{110}$ During the first year, cross-reactive antibodies appear to be protective against developing severe dengue, but with waning antibody titres over time, these cross-reactive antibodies then cause more severe dengue after about 2-3 years. ${ }^{11,112}$ In other words, travellers exposed to a second infection within the first 2 years may even be protected against severe dengue; disease enhancement is only observed after about 2-3 years, and this observation was also re-confirmed in the Sanofi Pasteur Phase 3 trials where the risk of severe dengue in seronegative vaccines was recognized after 30 months. ${ }^{113}$ Severe dengue is a multifactorial disease, it is hence important to re-emphasize that not only the time interval between the first and second infection, but also host factors, viral strain, age and experience in clinical management will determine any severe outcomes of the disease. ${ }^{55}$

Not all secondary infections lead to severe dengue. Apparently a certain ratio of antibody to virus is needed which, while not quantifiable, was documented in two large prospective studies. ${ }^{53,114}$ Immune correlates for both protection and for disease enhancement are sorely missing. ${ }^{115}$ The most frequently reported proportion of secondary infections leading to severe dengue is $2-4 \% .35,116$

So what is the relative risk of severe dengue in a secondary infection versus primary infection? In a retrospective study in Bangkok, among all cases of severe dengue, $84 \%$ were due to secondary infections, and Relative risks (RR) of severe dengue accompanying a secondary infection versus primary infection was around $7 .{ }^{117}$ However, the sample size was small. In a larger cohort study in 4-9 year old children in Indonesia, the risk of severe dengue (DHF) was $4 \%$ for secondary infections, and no severe cases were noted in primary infections. ${ }^{118}$ Another prospective study reported a RR of 3.4. ${ }^{119}$ The recent completion of the long-term Phase 3 trials of CYD-TDV dengue vaccine provides 5 years of hospital based surveillance reporting on cumulative incidence of severe dengue in the placebo group of seronegative versus seropositive children aged 2 to $16 .{ }^{113}$ The overall incidence over 5 years of severe dengue in seropositive individuals aged 2-16 was 6\%, whereas the cumulative incidence was $2.5 \%$ in seronegatives, mounting to a RR of 2.42. The RR of severe dengue was higher in those aged 2-8 versus those aged 9-16 (Table 2). 
Following recovery from a second infection a broadened immune response appears to be induced that prevents severe disease accompanying a third or fourth infection with different serotypes, as observed from natural cohort studies ${ }^{120}$, possibly explained by multitypic immunity. ${ }^{52}$

\section{Implications for Travel Medicine Practice}

\section{Pre-Travel:}

(1) Pre-travel Counseling

Every health care worker who counsels a prospective traveller to a dengue-endemic country has important educational responsibilities. He or she should prepare their patients to have a healthy trip. This includes guidance on how to avoid dengue infections but also clinical information to help the traveller be alert to the early or severe signs and symptoms of dengue should they occur during or shortly after their trip. It is a responsibility of travel medicine personnel or any physician who sees a febrile patient recently returned from a dengue endemic country (virtually any tropical destination) is to assure that the patient is promptly seen by competent infectious disease specialists and provided with a specific warning to recognize early signs of vascular leakage.

Counseling should include a fact-based description of the risk of being bitten by an infected Aedes aegypti or Aedes albopictus and accompanied by actionable advice on avoiding such bites. Excellent, authoritative and accessible information is available at the United States CDC "Dengue" website (https://www.cdc.gov/dengue/index.html). Aedes species are daytime biting mosquitoes that feed most actively in the early morning or late afternoon. Daytime visits to places where humans congregate including hotel grounds carries some risk of exposure to Aedes mosquitoes. A greater risk occurs during daytime visits to homes or short or long-term residence with local residents. It seems likely that airbnb or counterpart home-residence programs will contribute to an increase in travel-acquired dengue. The single most useful way to prevent Aedes bites is to stay inside air-conditioned structures. That may be impossible for the recreational tourist. Persons venturing into close contact with people in the country they are visiting should apply mosquito repellant to exposed skin prior to daytime exposure, particularly to the back of the neck, arms and legs. Unfortunately, compliance with repellent use on skin and clothing has been shown to be suboptimal in travellers. ${ }^{121}$ Potential difference of

the efficacy between DEET and picaridin containing insect repellents applied at the same dosage are minimal, with some evidence pointing to a superior persistence for picaridin. Where only $30 \%$ DEET or lower concentrations are available, then on current evidence, it is reasonable to offer 
DEET or picaridin as a first choice. Where $>50 \%$ DEET products are available then the protection time advantage associated with these formulations make them the first choice repellents. ${ }^{122}$

Pre-travel briefings should be accompanied by a description of a worst-case illness scenario. Adults with no recognized prior dengue infection are at risk to the dengue fever syndrome, a constellation of high fever, retro-orbital headache, gastrointestinal disturbances, aches and pains often described as "the worst illness I ever had." Young children without prior travel to dengue endemic countries may experience a mild febrile episode while the older child may experience variations of the dengue fever syndrome. If the travellers are residents in or VFR to dengue-endemic countries or have received the diagnosis of a prior dengue illness, counseling should include a description of dengue warning signs with strong emphasis that the traveller who develops a high fever should urgently seek competent medical care in a facility prepared to provide life-saving resuscitative care.

All travellers need to be aware that the risk of more severe dengue is higher after a second infection with a different serotype, but that severe disease can also occur after a primary infection. Seeking care in settings experienced in the clinical management of severe dengue is highly advised. All fevers longer than 3 days should always be further investigated. The critical phase usually starts on day 4 or 5 of illness (Figure 1). With timely care and good clinical management, case fatality rates should be below $0.1 \%$.

(2) Vaccines to prevent dengue infections in travellers

The high incidence of dengue in travellers to dengue endemic countries would justify pre-travel vaccination. ${ }^{123}$ The first licensed dengue vaccine, CYD-TDV (Dengvaxia $\left.{ }^{\circledR}\right)$, is a live attenuated, recombinant tetravalent vaccine employing the attenuated YF virus $17 \mathrm{D}$ strain as the replication backbone. However, its performance is serostatus dependent being protective and safe in seropositive individuals, but not recommended for dengue-naive travellers due to an excess risk of severe dengue. ${ }^{124}$ Offering the vaccine to seropositive travellers is therefore possible, however, there are four drawbacks: First, the proportion of seropositives amongst travellers is low. For example, 5.8\% of Italian travellers had dengue IgM and/or IgG antibodies. ${ }^{125}$ In Australian travellers, $4.4 \%$ were dengue IgG positive, and the number of prior trips to Asia was a predictor for higher dengue seropositivity. ${ }^{126}$ Second, there are no diagnostic assays that can reliably determine serostatus. ${ }^{127}$ Third, the vaccine is licensed for 3 doses, 6 months apart, which makes this vaccines practically unfeasible for last minute travellers. In 2018, CYD-TDV was approved by the European Medicine Agency for use in seropositive individuals, but use in travellers was not endorsed. In May 2019, CYD-TDV was also approved 
by the U.S. Food and Drug Administration (FDA) but the recommendations by American Committee on Immunization Practices (ACIP) whether it will be recommended for travellers is still outstanding. The risk-benefit assessment of a serostatus-dependent vaccine such as CYD-TDV differs between travellers and the endemic population. Two other live-attenuated chimeric dengue vaccines are currently in Phase 3 trials, the results of which should be available by end 2019 or early 2020. One is a mixture of attenuated dengue 2 and chimeric dengue 1,3 and 4 with backbone containing only the dengue 2 NS1 antigen, the other contains attenuated NS1-containing dengue 1,3 and 4 viruses and a dengue $2 / 4$ chimera. ${ }^{128}$ These vaccines should result in a very different serostatus dependent performance from that of CYD-TDV. Results of the Phase 3 trials are now eagerly awaited.

\section{Care for the Traveller with dengue during travel or after return from travel}

\section{Diagnosis}

The choice of laboratory test depends on the time since onset of fever. Before day 5 of illness, during the febrile period, dengue infections may be diagnosed by virus isolation, by nucleic acid amplification tests such as reverse transcriptase-polymerase chain reaction (RT-PCR), or by detection of viral antigens such as the dengue non-structural protein 1 (NS1) by enzyme-linked immunosorbent assay (ELISA) or rapid diagnostic tests (RDTs). After day 4-5, dengue viruses and antigens disappear from the blood coincident with the appearance of dengue-specific antibodies, hence serological assays should be used. ${ }^{129}$ NS1 is longer positive than PCR, and hence the window for diagnosis is longer for NS1 based tests, especially in primary dengue. ${ }^{130}$

Antibody response to dengue infection differs according to the immune status of the host. Patients not previously infected with a flavivirus develop a primary response characterized by a slow increase of specific antibodies. Dengue IgM antibodies are detected in about $50 \%$ of patients after days $3-5$, increasing to $80 \%$ by day 5 and $99 \%$ by day $10 .{ }^{12}$ It is wise to wait until at least 5 days after onset of fever to interpret results of a $n$ IgM/IgG ELISA or rapid diagnostic test. IgM levels peak after 2 weeks and then decline to undetectable levels over 2-3 months. After primary dengue infections, anti-dengue IgG may be detected at low levels by the end of the first week (often only from day 10 onwards); the level increases slowly thereafter, and is thought to persist for life. In patients with a previous dengue (or other flavivirus) infection, dengue IgG titres 
rise rapidly within the first week of illness. Serology does not determine the infecting virus serotype, is susceptible to cross-reactivity with other flaviviruses, and often requires paired acute and convalescent samples for confirmatory testing.

The combination of NS1 antigen and IgM testing at point of care offers a longer diagnostic window and has revolutionized the diagnosis of dengue. Cross-reactivity with Zika virus and other flaviviruses is reported for all serological assays. Serostatus, reflecting whether or not the individual has experienced a dengue infection in the past, is determined by a serological assay. The specificity of a serological assay will depend on the extent of exposure to other flaviviruses, or vaccination with flavivirus vaccines such as TBE, YF or JE vaccines. No RDT has yet been validated or licensed specifically for the purpose of determining dengue-specific serostatus. ${ }^{131}$ Currently available RDTs that contain dengue IgG were developed to diagnose acute infections, with the dengue IgG component added to identify IgG dengue antibodies to diagnose a secondary dengue infection.

\section{Differential diagnosis}

A wide variety of conditions, primarily viral infections but also bacterial and parasitic diseases must be considered in the differential diagnosis depending on local disease epidemiology, travel history, incubation time and the clinical picture. A very similar clinical disease to dengue occurs in many of the same travel destinations caused by chikungunya and Zika viruses, all transmitted by identical vector mosquitoes. Given the wide range of differential diagnosis, it is of utmost importance to exclude treatable diseases such as malaria and typhoid fever that can initially present similarly with fever and thrombocytopenia in order to institute prompt life-saving specific treatment.

\section{Clinical manifestations of severe dengue and management}

Clinical management of uncomplicated classical dengue fever has been reviewed extensively elsewhere and basically consists of symptomatic care, usually done on an outpatient basis, as long as daily monitoring of platelets and hematocrit is possible, and the patient is instructed to recognize warning symptoms and signs. ${ }^{81}$ Admission criteria vary by countries. Singapore, a low dengue endemic country, has proposed the following admission criteria: 
- Objective criteria include significant bleeding, fall in blood pressure, dehydration and/or postural hypotension, a rise in the hematocrit $\geq$ $20 \%$ above baseline, and a platelet count of less than $50,000 / \mathrm{mm}^{3}$ in adults or less than $80,000 / \mathrm{mm}^{3}$ in children.

- Subjective criteria include severe vomiting or diarrhea, severe abdominal pain, persistent fever, dizziness, and age $\geq 65$ years.

With these criteria, the number of unnecessary hospitalisation was drastically reduced, without a concomitant increase in adverse clinical outcomes. $^{132}$

In the following, we focus on the management of severe dengue to reduce mortality. Every travel medicine provider and physician caring for ill returned travellers should be familiar with the clinical management of increased vascular permeability leading to intravascular volume depletion is the hall mark of severe dengue, which may progress to life-threatening dengue shock syndrome. Three Phases can be observed: the febrile phase with rapid decrease of platelets and increase of haematocrit, the critical phase, the recovery phase (Figure 1). Warning signs often occur at the time of defervescence and usually include irritability, abdominal pain, vomiting. Clinical detection of vascular permeability is based on a range of symptoms, signs and laboratory parameters, and as the progression to severe dengue can occur rapidly, such clinical assessments need to be done frequently, especially on days 4-6 of illness. Haemoconcentration of $20 \%$ or more is evidence of plasma leakage, ${ }^{133}$ but for individual case management this criterion is hard to apply since the baseline haematocrit is often not known, and hydration may mask this increase. Similarly, serosal effusions (pleural, peritoneal, and sometimes pericardial) reflect the severity of the vasculopathy but are difficult to detect clinically, and hence serial ultrasound investigations should be used to identify such vascular leakage. ${ }^{134}$ Ultrasound examination can detect plasma leakage in multiple body compartments, with ultrasonographic signs of plasma leakage preceding changes in hematocrits, sometimes even detectable in the first few days of illness. ${ }^{46}$ Thickening of the gallbladder wall can frequently be detected, and is not necessarily a sign of severe dengue, as it can be detected in mild cases or primary infections. ${ }^{46}$, nor is sub-clinical perihepatic and perisplenic ascites. ${ }^{135}$ Pleural effusion and clinically apparent ascites are associated with progression to dengue hemorrhaegic fever. ${ }^{134}$ Reflecting volume depletion, a highly characteristic phenomenon may be observed which should be taken very seriously: narrowing of the pulse pressure. The pulse pressure is the difference between systolic and diastolic pressure. In early severe dengue, the diastolic pressure rises while the systolic pressure is maintained, resulting in narrowing of the pulse pressure. When the PP narrows to $20 \mathrm{mmHg}$ or less, the patient is defined as having impending dengue shock. Although the patient may appear alert and well, the significance of the narrow pulse pressure must not be ignored since without prompt fluid resuscitation the patient may 
deteriorate rapidly. Clinical evidence of organ impairment is observed less frequently, except as a secondary phenomenon or in individuals with underlying diseases. ${ }^{85}$ Asymptomatic hepatomegaly and mild to moderate elevations of liver transaminases are extremely common (both in primary and secondary dengue), but fuliminant hepatitis is usually associated with secondary infection. ${ }^{136}$

In the absence of effective antiviral or immunosuppressive therapy, good supportive care is the cornerstone to reduce fatal outcomes. Prompt recognition and immediate fluid resuscitation is crucial. Titrating sufficient fluid replacement to maintain adequate intravascular volume for 48-72 hours until the vasculopathy reverses is the art of good clinical management of severe dengue. ${ }^{81}$ Fluid overload is a mistake of inexperienced clinicians that may result in pulmonary oedema and death. Figure 2 displays the consequences of too little or too much fluid. Causes of death are often related to either of the three delays: delay in admitting a patient with warning signs, delay in initiating fluid therapy during the critical phase, or delay in discontinuing fluid resuscitation in the recovery phase. Algorithms for the clinical management of compensated and decompensated shock both for adults and children are available from WHO`s 2009 Guideline on Diagnosis, Treatment, Prevention and Control Clinical. ${ }^{137}$ The use of prophylactic platelet transfusions for moderate to severe thrombocytopenia without clinical bleeding is controversial. In a recent trial in Asian adults with platelet counts below 20,000, prophylactic platelet transfusion was not superior to supportive care in preventing bleeding, but was associated with more adverse events. ${ }^{138}$ Significant predictors for mortality include gastrointestinal bleeding $<72 \mathrm{~h}$ after presentation, and haemoconcentration and leukocytosis after hospitalization. ${ }^{139}$ Fluid resuscitation in pregnant women, small children, and those with co-morbidities need adapted fluid resuscitation and more frequent monitoring.

The increased vascular permeability and abnormal haemostasis are in most cases transient and resolve within 48-72 hours under good clinical management, but individuals with post-dengue illness often remain tired and lethargic for weeks. Recovery can be particularly prolonged in adults, who may experience profound fatigue, myalgia and depression for weeks to months after the acute illness has resolved, irrespective of dengue severity. ${ }^{140}$

Severe disease outcomes other than dengue shock syndrome: Although vascular leakage is the hallmark of severe dengue, other unsuual severe complications can also occur. Unusual complications include myocarditis ${ }^{141}$, other cardiac problems ${ }^{87,141,142}$ and fulminant hepatitis. ${ }^{143}$ Dengue can manifest with a wide range of neurological features, which have been noted in $0.5-21 \%$ of patients with dengue admitted to hospital. ${ }^{144}$ Although the association of Zika with Guillain-Barre Syndrome is much stronger, dengue can also trigger Guillain-Barre Syndrome. ${ }^{145,146}$ Haemophagocytic 
syndrome is a rare event, but should be suspected in dengue cases with prolonged fever. The clinical picture is characterized by persistent high fever, variable cytopenia and multi-organ failure associated with macrophage activation, haemophagocytosis and hypercytokinaemia. ${ }^{147}$ Table 4 summarizes rare severe dengue related complications, described in the endemic and travellers populations.

\section{Conclusions:}

As in the endemic population, dengue has a high morbidity but low mortality in travellers. Although dengue is a frequent cause of travel illness, severe dengue and deaths are rare. Nevertheless, dengue infections can interrupt travel, lead to evacuation and major out-of-pocket costs. Dengue is more frequent than many other travel-related vaccine preventable diseases such as hepatitis A, hepatitis B, rabies, Japanese encephalitis, and yellow fever, indicating a powerful need for a dengue vaccine for travellers. Results of efficacy trials of two new tetravalent dengue vaccines are imminent.

Author contributions: AWS wrote the first draft, and created the tables. SH and AWS wrote the final draft. 
Table 1: Attack rates, incidence rates and seroconversion rates of dengue infections in travellers

\begin{tabular}{|c|c|c|c|c|c|c|c|c|c|}
\hline No. & $\begin{array}{l}\text { Attack rate } \\
(\mathrm{AR})\end{array}$ & $\begin{array}{l}\text { Incidence Rate } \\
\text { (IR) }\end{array}$ & $\begin{array}{l}\text { Seroconversi } \\
\text { on Rate }\end{array}$ & $\begin{array}{l}\text { No. of } \\
\text { travellers }\end{array}$ & $\begin{array}{l}\text { Origin } \\
\text { travellers }\end{array}$ & $\begin{array}{l}\text { Year of } \\
\text { publication }\end{array}$ & Study design & Reference & Remarks \\
\hline 1 & $\begin{array}{l}6.5 \%(95 \% \text { CI: } \\
45-8.5)\end{array}$ & $\begin{array}{l}13.9 \text { person- } \\
\text { months } \quad(95 \% \\
\text { CI: } 9.9-19.1)\end{array}$ & & 600 & Netherlands & 2018 & Prospective & $\begin{array}{l}\text { Overbosch FW, Schinkel J, } \\
\text { Stolte IG, Prins M, Sonder GJB } \\
\text { (2018). Dengue virus infection } \\
\text { among long-term travellers } \\
\text { from the Netherlands: A } \\
\text { prospective study, 2008-2011. } \\
\text { PLoS One.13(2):e0192193 }\end{array}$ & \\
\hline 2 & $* 2.7 \%$ & & & 277 & America & 2017 & Prospective & $\begin{array}{l}\text { Lindholm DA, Myers T, } \\
\text { Widjaja S, Grant EM, Telu K, } \\
\text { Lalani T, Fraser J, Fairchok M, } \\
\text { Ganesan A, Johnson MD, Kunz } \\
\text { A, Tribble DR, Yun HC (2017). } \\
\text { Mosquito Exposure and } \\
\text { Chikungunya and Dengue } \\
\text { Infection Among Travellers } \\
\text { During the Chikungunya } \\
\text { Outbreak in the Americas. Am J } \\
\text { Trop Med Hyg. 96(4):903-912. }\end{array}$ & $\begin{array}{l}* \text { Only } 117 \text { pa } \\
\text { sera are availi } \\
\text { for pre- and } 1 \\
\text { travel }\end{array}$ \\
\hline 3 & & $\begin{array}{l}17.6 \quad \text { per } \\
10,000 \\
\text { deployment } \\
\text { months }\end{array}$ & $1.5 \%$ & 1000 & America & 2017 & Retrospective & $\begin{array}{l}\text { Hesse EM, Martinez LJ, Jarman } \\
\text { RG, Lyons AG, Eckels KH, De } \\
\text { La Barrera RA, Thomas SJ } \\
\text { (2017). Dengue Virus } \\
\text { Exposures Among Deployed } \\
\text { U.S. Military Personnel. Am J } \\
\text { Trop Med Hyg. 96(5):1222- } \\
1226 .\end{array}$ & \\
\hline 4 & & $\begin{array}{l}* 58.7 \text { per } \\
1000 \text { person- } \\
\text { months of } \\
\text { travel }(95 \% \mathrm{CI}:\end{array}$ & $\begin{array}{l}* 6.8 \% \\
{ }^{*} 2.9 \%\end{array}$ & 589 & America & 2016 & Prospective & $\begin{array}{l}\text { Olivero RM, Hamer } \text { DH, } \\
\text { MacLeod WB, Benoit CM, } \\
\text { Sanchez-Vegas C, Jentes ES, } \\
\text { Chen LH, Wilson ME, Marano } \\
\text { N, Yanni EA, Ooi WW, }\end{array}$ & $\begin{array}{l}\text { *those who a } \\
\text { DENV IgM } \\
\text { IgG positive u } \\
\text { excluded f } \\
\text { denominator }\end{array}$ \\
\hline
\end{tabular}




\begin{tabular}{|c|c|c|c|c|c|c|c|c|c|}
\hline & & $\begin{array}{l}39.2-78.1) \\
{ }^{\#} 28.7 \text { per } 1000 \\
\text { person-months } \\
\text { of travel }(95 \% \\
\text { CI: } 14.7-42.8)\end{array}$ & & & & & & $\begin{array}{l}\text { Karchmer AW, Kogelman L, } \\
\text { Barnett ED (2016). Dengue } \\
\text { virus seroconversion in } \\
\text { travellers to dengue-endemic } \\
\text { areas. Am J Trop Med Hyg. } \\
95(5): 1130-1136\end{array}$ & $\begin{array}{l}\text { numerator } \\
{ }^{\#} \text { removal of fa } \\
\text { positive } \\
\text { based on PR } \\
\text { data suppor } \\
\text { cross-reactivity } \\
\text { with o } \\
\text { flavivirus } \\
\text { vaccines }\end{array}$ \\
\hline 5 & & $\begin{array}{l}\text { *3.4 per } 1000 \\
\text { person-months } \\
\text { of travel } \\
(95 \% \text { CI: } 1.9- \\
5.8)\end{array}$ & $\begin{array}{l}* 6.3 \% \\
(95 \% \text { CI: } 3.4- \\
10.6)\end{array}$ & 652 & New Zealand & 2013 & Retrospective & $\begin{array}{l}\text { Visser JT, Edwards CA (2013). } \\
\text { Dengue fever, tuberculosis, } \\
\text { human immunodeficiency virus, } \\
\text { and hepatitis C virus conversion } \\
\text { in a group of long-term } \\
\text { development aid workers. J } \\
\text { Travel Med. 20(6):361-7 }\end{array}$ & $\begin{array}{l}\text { *based on } \\
\text { paired sera }\end{array}$ \\
\hline 6 & 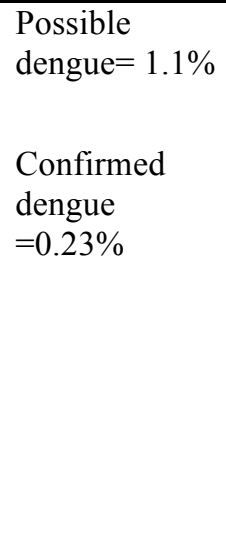 & 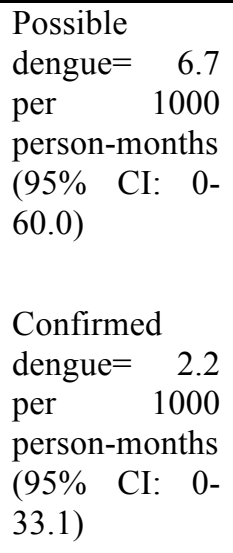 & & 285 & Switzerland & 2013 & Prospective & $\begin{array}{l}\text { Leder K, Mutsch M, } \\
\text { Schlagenhauf } \mathrm{P} \text {, Luxemburger } \\
\text { C, Torresi J (2013). } \\
\text { Seroepidemiology of dengue in } \\
\text { travellers: a paired sera } \\
\text { analysis. Travel Med Infect Dis. } \\
\text { 11(4):210-3 }\end{array}$ & $\begin{array}{l}{ }^{\#} \text { confirmed } \\
\text { dengue } \\
\text { calculation } \\
\text { based on remi } \\
\text { of those who } \\
\text { received } \\
\text { vaccine } \\
\text { travel) }\end{array}$ \\
\hline 7 & & $\begin{array}{l}8.57 \text { per } 1000 \\
\text { person-months } \\
(95 \% \text { CI: } 5.90 \\
-12.0)\end{array}$ & $\begin{array}{l}4.91 \%(95 \% \\
\text { CI: } \quad 3.4 \quad- \\
6.83)\end{array}$ & & New Zealand & 2012 & Retrospective & $\begin{array}{l}\text { Visser JT, Narayanan A, } \\
\text { Campbell } \\
\text { Strongyloides, dengue fever, } \\
\text { and tuberculosis conversions in } \\
\text { New Zealand police deploying } \\
\text { overseas. J } \\
\text { 19(3):178-82 }\end{array}$ & \\
\hline
\end{tabular}




\begin{tabular}{|c|c|c|c|c|c|c|c|c|c|}
\hline 8 & & $\begin{array}{l}3.4 \text { per } 10,000 \\
\text { days of travel } \\
(95 \% \text { CI: } 0.9- \\
8.7)\end{array}$ & $1.0 \%$ & 467 & Australia & 2012 & Prospective & 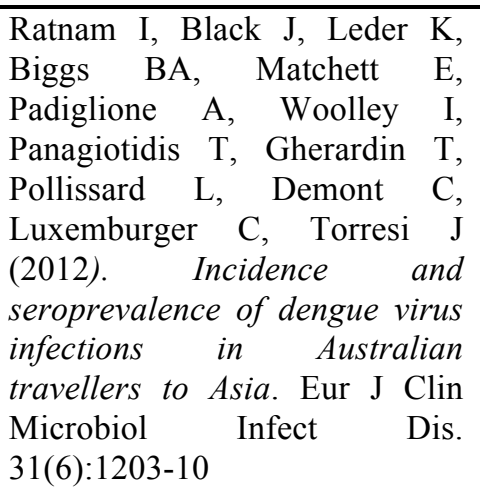 & $\begin{array}{l}\text { *based on } \\
\text { samples } \\
\text { paired sera }\end{array}$ \\
\hline 9 & & $\begin{array}{l}14.6 \text { per } 1000 \\
\text { person-months } \\
(95 \% \text { CI: } 8.3- \\
23.9)\end{array}$ & $\begin{array}{l}1.2 \% \quad(95 \% \\
\text { CI: } 0.66 \quad- \\
1.9)\end{array}$ & 1207 & Netherlands & 2011 & Prospective & $\begin{array}{l}\text { Baaten GG, Sonder GJ, Zaaijer } \\
\text { HL, van Gool T, Kint JA, van } \\
\text { den Hoek A (2011). Travel- } \\
\text { related dengue virus infection, } \\
\text { The Netherlands, 2006-2007. } \\
\text { Emerg Infect Dis. 17(5):821-8. }\end{array}$ & \\
\hline 10 & $\begin{array}{l}2.9 \% \text { (95\% CI: } \\
1.6-4.9)\end{array}$ & $\begin{array}{l}30 \text { per } 1000 \\
\text { person-months } \\
(17.4-51.6)\end{array}$ & & 447 & Netherlands & 2002 & Prospective & $\begin{array}{l}\text { Cobelens FG, Groen J, } \\
\text { Osterhaus AD, Leentvaar- } \\
\text { Kuipers A, Wertheim-van } \\
\text { Dillen PM, Kager PA (2002). } \\
\text { Incidence and risk factors of } \\
\text { probable dengue virus infection } \\
\text { among Dutch travellers to Asia. } \\
\text { Trop Med Int Health. 7(4):331- } \\
\text { 8. }\end{array}$ & \\
\hline 11 & & & $\begin{array}{l}6.7 \% \quad(95 \% \\
\text { CI: } 2.7-13.3)\end{array}$ & 104 & Israel & 1999 & Prospective & $\begin{array}{l}\text { Potasman I, Srugo I, Schwartz E } \\
\text { (1999). Dengue seroconversion } \\
\text { among Israeli travellers to } \\
\text { tropical countries. Emerg Infect } \\
\text { Dis. 5(6):824-7. }\end{array}$ & \\
\hline 12 & $\begin{array}{l}3.4 \text { per } 1000 \\
\text { travellers } \\
(95 \% \text { CI: } 2- \\
5.4)\end{array}$ & & & 5030 & Israel & 2000 & Observational & $\begin{array}{l}\text { Schwartz E, Moskovitz A, } \\
\text { Potasman I, Peri G, Grossman } \\
\text { Z, Alkan ML Changing } \\
\text { epidemiology of dengue fever in }\end{array}$ & $\begin{array}{l}* * \text { the AR is } \\
\text { per } 1000 \text { pers } \\
\text { months. That } \\
\text { be the IR. AF }\end{array}$ \\
\hline
\end{tabular}




\begin{tabular}{|c|c|c|c|c|c|c|c|c|}
\hline & & & & & & & $\begin{array}{l}\text { travellers to Thailand. Eur J } \\
\text { Clin Microbiol Infect Dis. } 2000 \\
\text { Oct;19(10):784-6 }\end{array}$ & $\begin{array}{l}\text { calculated as } \\
1000 \text { travellers }\end{array}$ \\
\hline 13 & & $\begin{array}{l}4.28 \text { per } 1000 \\
\text { person-months } \\
(2.4-6.16)\end{array}$ & 162 & Gabon & 2016 & Prospective & $\begin{array}{l}\text { Gabor JJ, Schwarz NG, Esen M, } \\
\text { Kremsner PG, Grobusch MP. } \\
\text { Dengue and chikungunya } \\
\text { seroprevalence in Gabonese } \\
\text { infants prior to major outbreaks } \\
\text { in 2007 and 2010: A sero- } \\
\text { epidemiological study.Travel } \\
\text { Med Infect Dis. 2016 Jan- } \\
\text { Feb;14(1):26-31 }\end{array}$ & \\
\hline 14 & $1.19 \%$ & & 335 & Germany & 2002 & $\begin{array}{l}\text { Cross-sectional / } \\
\text { Observational }\end{array}$ & $\begin{array}{l}\text { Stephan C, Allwinn R, Brodt } \\
\text { HR, Knupp B, Preiser W, Just- } \\
\text { Nübling G (2002). Travel- } \\
\text { acquired dengue infection: } \\
\text { clinical spectrum and diagnostic } \\
\text { aspects. Infection. 30(4):225-8 }\end{array}$ & $* 4$ seroconvert \\
\hline 15 & 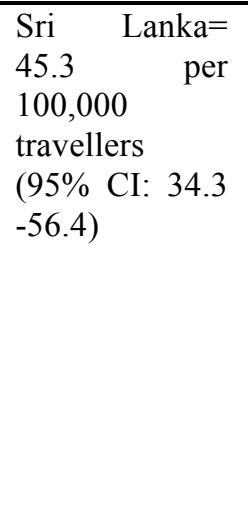 & & 925 & Sweden & 2014 & Retrospective & $\begin{array}{l}\text { Rocklöv J, Lohr W, Hjertqvist } \\
\text { M, Wilder-Smith A (2014). } \\
\text { Attack rates of dengue fever in } \\
\text { Swedish travellers. Scand J } \\
\text { Infect Dis. 46(6):412-7 }\end{array}$ & $\begin{array}{l}\text { *calculated fo } \\
\text { countries } \\
\text { highest AR. } \\
\text { Bangladesh } \\
42.6 \text { per 100, } \\
\text { travellers (C, } \\
\text { CI: 23.8-61.5) } \\
\text { El Salvador } \\
=33.4 \text { per } 10( \\
\text { travellers (C, } \\
\text { CI: } 10.0-56.8)\end{array}$ \\
\hline
\end{tabular}


Table 2: Relative Risk (RR) of severe dengue in seronegative compared with seropositive children; data derived from the placebo group in the Phase 3 trials of the CYD-TDV dengue vaccine ${ }^{113}$

\begin{tabular}{|l|l|l|l|}
\hline $\begin{array}{l}\text { Cumulative incidence (CI) of severe dengue per 1,000 unvaccinated } \\
\text { children in the Phase 3 trial CYD-TDV }\end{array}$ & $\begin{array}{c}\text { Relative } \\
\text { Risk (RR) }\end{array}$ & RR \\
\hline \begin{tabular}{l} 
2-8 years old \\
\hline
\end{tabular} & Seronegative & Seropositive & \\
\hline $\begin{array}{l}\text { Multiple imputations methods } \\
\text { Months 0-60 }\end{array}$ & 3.64 & 11.6 & 3.19 \\
\hline 9-16 years old & 1.74 & 4.80 & RR \\
\hline $\begin{array}{l}\text { Multiple imputations methods } \\
\text { Months 0-60 }\end{array}$ & 2.52 & 6.09 & 2.76 \\
\hline 2-16 years old & RR \\
\hline $\begin{array}{l}\text { Multiple imputations methods } \\
\text { Months 0-60 }\end{array}$ & 2.42 \\
\hline
\end{tabular}


Table 3: Overview on pertinent data with regards to risk of severe dengue associated with secondary infections derived from studies in dengue endemic populations

\section{Key messages}

About $2-4 \%$ of secondary infections lead to severe dengue

The proportion of infections that are symptomatic for first infections as $0.18,0.13$ for individuals infected in the year following

109

a first infection and $0.4 \%$ for those experiencing secondary infections after this first year.

Among all cases of severe dengue, $84 \%$ are due to secondary infection

Relative Risk of severe dengue as a result of secondary infection versus primary dengue infection is 7 (Thailand)

Relative risk of severe dengue as a result of secondary infection versus primary infection is 3.4 (Indonesia)

Relative risk of severe dengue as a result of secondary infections versus primary infection is 3.19 (age 2-8) (10 dengue

countries) 
Table 4: Examples of rare complications of dengue infection in the endemic and travellers population

\begin{tabular}{lll}
\hline & Diagnoses & Selected references \\
\hline Cardiovascular & Myocarditis & 141 \\
Liver & Bradycardia & $87,141,142$ \\
Neurology & Fulminant hepatitis & 143 \\
& Encephalopathy & 148 \\
& Encephalitis & 148 \\
& Cerebral infarcts & 148,149 \\
& Guillain-Barre Syndrome & $145,146,150-154$ \\
Eye & Abducence nerve palsy & 155 \\
& Rhabdomyolysis & 156 \\
& Retinal vasculopathy and optic & 144 \\
& neuropathy & 157 \\
& Optic neuritis & 147 \\
\hline
\end{tabular}


Figure 1: Time course of dengue illness by day (Source: WHO TDR ${ }^{137}$ )

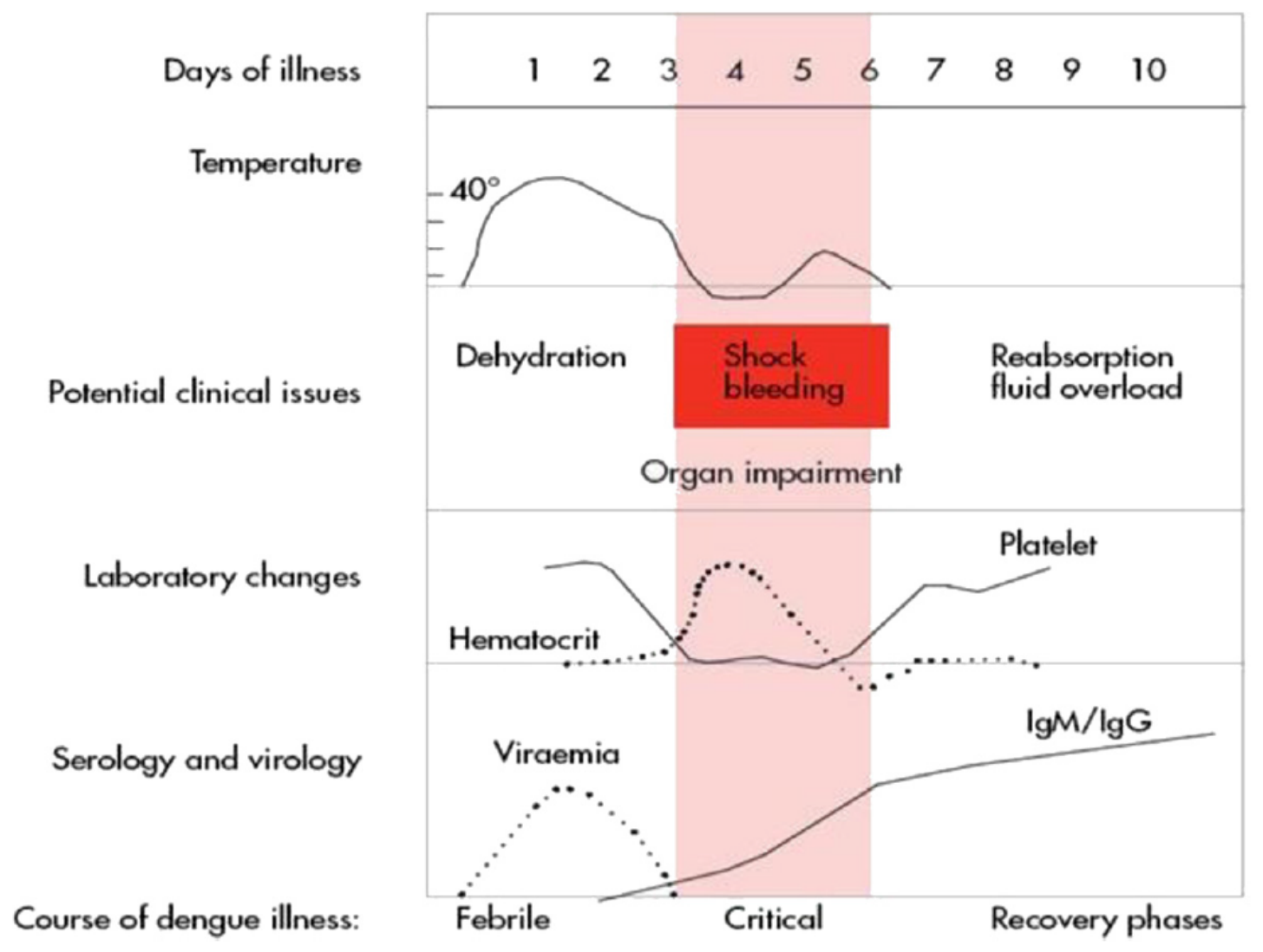


Figure 2: IV fluid therapy for severe dengue ((Source: WHO TDR ${ }^{137}$ )

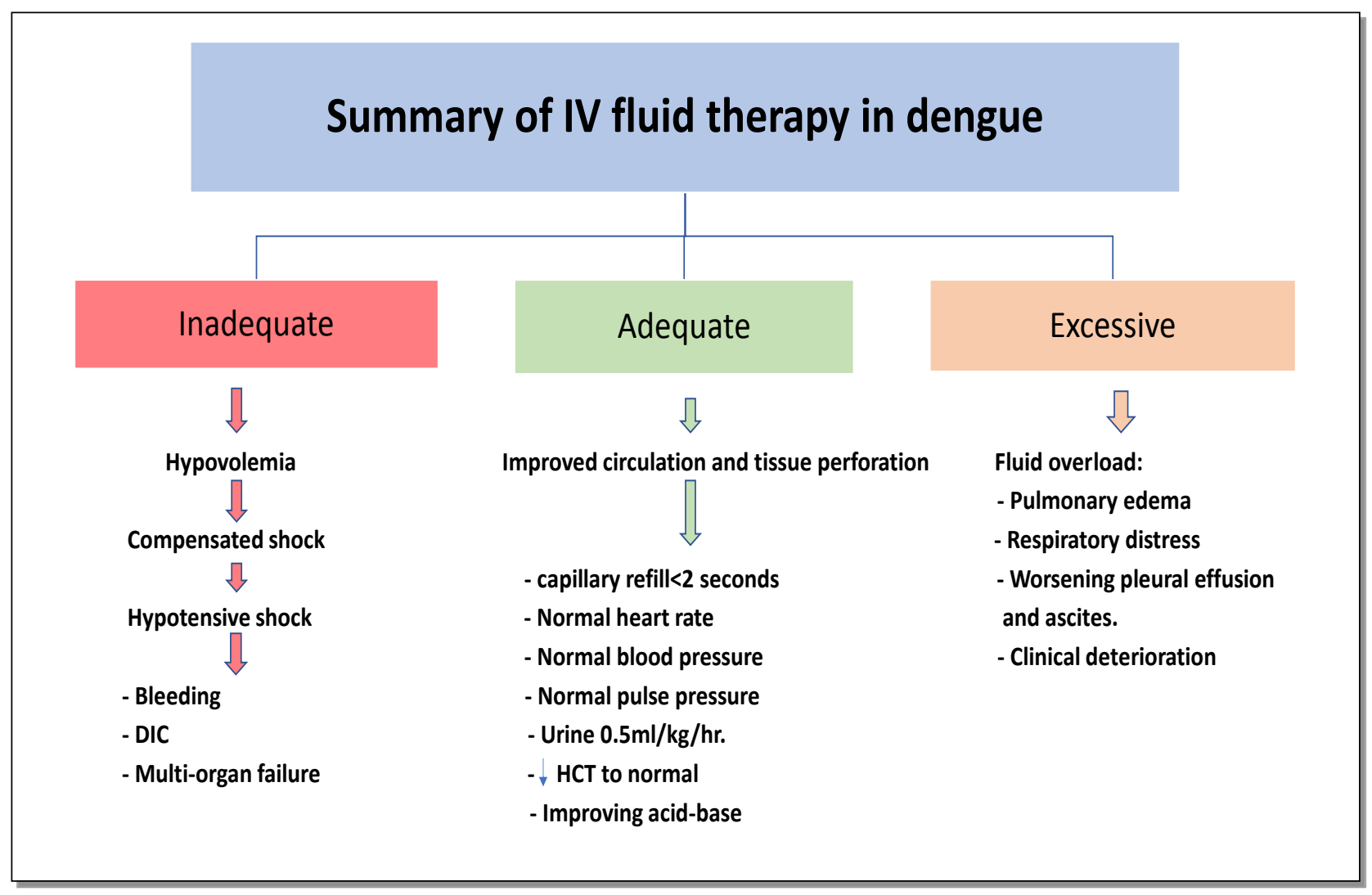


References:

1. Wilder-Smith A, Gubler DJ, Weaver SC, Monath TP, Heymann DL, Scott TW. Epidemic arboviral diseases: priorities for research and public health. Lancet Infect Dis 2017; 17(3): e101-e6.

2. Global Burden of Disease Cancer C, Fitzmaurice C, Allen C, et al. Global, Regional, and National Cancer Incidence, Mortality, Years of Life Lost, Years Lived With Disability, and Disability-Adjusted Life-years for 32 Cancer Groups, 1990 to 2015: A Systematic Analysis for the Global Burden of Disease Study. JAMA oncology 2017; 3(4): 524-48.

3. Horstick O, Tozan Y, Wilder-Smith A. Reviewing dengue: still a neglected tropical disease? PLoS Negl Trop Dis 2015; 9(4): e0003632.

4. Stanaway JD, Shepard DS, Undurraga EA, et al. The global burden of dengue: an analysis from the Global Burden of Disease Study 2013. Lancet Infect Dis 2016.

5. Leder K, Torresi J, Brownstein JS, et al. Travel-associated illness trends and clusters, 2000-2010. Emerging infectious diseases 2013; 19(7): 1049-73.

6. Wilson ME, Weld LH, Boggild A, et al. Fever in returned travelers: results from the GeoSentinel Surveillance Network. Clin Infect Dis 2007; 44(12): 1560-8.

7. Schwartz E, Weld LH, Wilder-Smith A, et al. Seasonality, annual trends, and characteristics of dengue among ill returned travelers, 19972006. Emerg Infect Dis 2008; 14(7): 1081-8.

8. Streit JA, Yang M, Cavanaugh JE, Polgreen PM. Upward Trend in Dengue Incidence among Hospitalized Patients, United States. Emerging Infectious Diseases 2011; 17(5): 914-6.

9. Rocklov J, Lohr W, Hjertqvist M, Wilder-Smith A. Attack rates of dengue fever in Swedish travellers. Scand J Infect Dis 2014; 46(6): 412-7. 10. Cobelens FG, Groen J, Osterhaus AD, Leentvaar-Kuipers A, Wertheim-van Dillen PM, Kager PA. Incidence and risk factors of probable dengue virus infection among Dutch travellers to Asia. Trop Med Int Health 2002; 7(4): 331-8.

11. Gautret P, Simon F. Dengue, chikungunya and Zika and mass gatherings: What happened in Brazil, 2014. Travel Med Infect Dis 2016; 14(1): 7-8.

12. Sadarangani SP, Lim PL, Vasoo S. Infectious diseases and migrant worker health in Singapore: a receiving country's perspective. J Travel Med 2017; 24(4).

13. Wilder-Smith A. Risk of Dengue in Travelers: Implications for Dengue Vaccination. Curr Infect Dis Rep 2018; 20(12): 50.

14. Polwiang S. The estimation of imported dengue virus from Thailand. J Travel Med 2015; 22(3): 194-9.

15. Lagi F, Zammarchi L, Strohmeyer M, et al. Imported dengue fever in Tuscany, Italy, in the period 2006 to 2012. J Travel Med 2014; 21(5): 340-3.

16. Cnops L, Franco L, Van Meensel B, Van den Ende J, Paz Sanchez-Seco M, Van Esbroeck M. Three cases of imported dengue virus infection from Madeira to Belgium, 2012. J Travel Med 2014; 21(5): 344-8.

17. Masyeni S, Yohan B, Somia IKA, Myint KSA, Sasmono RT. Dengue infection in international travellers visiting Bali, Indonesia. J Travel Med 2018; 25(1). 
18. Poddighe D, Bonomelli I, Giardinetti S, Nedbal M, Bruni P. Paediatric Dengue Fever diagnosed through parents' epidemiologic report and preventive strategy during the acute phase of infection. J Travel Med 2016; 23(1).

19. Rabinowicz S, Schwartz E. Morbidity among Israeli paediatric travellers. J Travel Med 2017; 24(6).

20. Quam MB, Sessions O, Kamaraj US, Rocklov J, Wilder-Smith A. Dissecting Japan's Dengue Outbreak in 2014. Am J Trop Med Hyg 2016; 94(2): 409-12.

21. Lopez LF, Amaku M, Coutinho FA, et al. Modeling Importations and Exportations of Infectious Diseases via Travelers. Bull Math Biol 2016; 78(2): 185-209.

22. Quam MB, Wilder-Smith A. Importation index of dengue to determine the most probable origin of importation. J Travel Med 2015; 22(1):

72.

23. Quam MB, Khan K, Sears J, Hu W, Rocklov J, Wilder-Smith A. Estimating air travel-associated importations of dengue virus into Italy. J Travel Med 2015; 22(3): 186-93.

24. Wilder-Smith A, Quam M, Sessions O, et al. The 2012 dengue outbreak in Madeira: exploring the origins. Euro Surveill 2014; 19(8):

20718.

25. Sessions OM, Khan K, Hou Y, et al. Exploring the origin and potential for spread of the 2013 dengue outbreak in Luanda, Angola. Glob Health Action 2013; 6: 21822.

26. Neumayr A, Munoz J, Schunk M, et al. Sentinel surveillance of imported dengue via travellers to Europe 2012 to 2014: TropNet data from the DengueTools Research Initiative. Euro Surveill 2017; 22(1).

27. Massad E, Amaku M, Coutinho FAB, et al. Estimating the probability of dengue virus introduction and secondary autochthonous cases in Europe. Sci Rep 2018; 8(1): 4629.

28. Amarasinghe A, Kuritsk JN, Letson GW, Margolis HS. Dengue virus infection in Africa. Emerging infectious diseases 2011; 17(8): 1349-54.

29. Wilder-Smith A, Schwartz E. Dengue in travelers. N Engl J Med 2005; 353(9): 924-32.

30. Tozan Y, Headley TY, Sewe MO, et al. A Prospective Study on the Impact and Out-of-Pocket Costs of Dengue Illness in International Travelers. Am J Trop Med Hyg 2019.

31. Reiter P. Aedes albopictus and the world trade in used tires, 1988-1995: the shape of things to come? J Am Mosq Control Assoc 1998; 14(1): 83-94.

32. Molton JS, Low I, Choy MMJ, et al. Dengue virus not detected in human semen. J Travel Med 2018; 25(1).

33. Wilder-Smith A. Can dengue virus be sexually transmitted? J Travel Med 2019; 26(3).

34. Aye KS, Charngkaew K, Win N, et al. Pathologic highlights of dengue hemorrhagic fever in 13 autopsy cases from Myanmar. Hum Pathol 2014; 45(6): 1221-33.

35. Halstead SB. Dengue Antibody-Dependent Enhancement: Knowns and Unknowns. Microbiol Spectr 2014; 2(6).

36. Chareonsirisuthigul T, Kalayanarooj S, Ubol S. Dengue virus (DENV) antibody-dependent enhancement of infection upregulates the production of anti-inflammatory cytokines, but suppresses anti-DENV free radical and pro-inflammatory cytokine production, in THP-1 cells. J Gen Virol 2007; 88(Pt 2): 365-75. 
37. Ubol S, Phuklia W, Kalayanarooj S, Modhiran N. Mechanisms of immune evasion induced by a complex of dengue virus and preexisting enhancing antibodies. J Infect Dis 2010; 201(6): 923-35.

38. Halstead SB, Mahalingam S, Marovich MA, Ubol S, Mosser DM. Intrinsic antibody-dependent enhancement of microbial infection in macrophages: disease regulation by immune complexes. Lancet Infect Dis 2010; 10(10): 712-22.

39. Ubol S, Halstead SB. How Innate Immune Mechanisms Contribute to Antibody-Enhanced Viral Infections. Clin Vaccine Immunol 2010; 17(12): 1829-35.

40. Kliks SC, Nimmanitya S, Nisalak A, Burke DS. Evidence that maternal dengue antibodies are important in the development of dengue hemorrhagic fever in infants. Am J Trop Med Hyg 1988; 38(2): 411-9.

41. Halstead SB, Lan NT, Myint TT, et al. Infant dengue hemorrhagic fever: Research opportunities ignored. Emerg Infect Dis 2002; 12: 1474-

9.

42. Halstead SB. Dengue vascular permeability syndrome: What no T cells? Clin Infect Dis 2013; 56(6): 900-1.

43. Cohen SN, Halstead SB. Shock associated with dengue infection. I. Clinical and physiologic manifestations of dengue hemorrhagic fever in Thailand, 1964. JPediatrics 1966; 68: 448-56.

44. Nimmannitya S, Halstead SB, Cohen S, Margiotta MR. Dengue and chikungunya virus infection in man in Thailand, 1962-1964. I.

Observations on hospitalized patients with hemorrhagic fever. AmJTropMedHyg 1969; 18(6): 954-71.

45. Colbert JA, Gordon A, Roxelin R, et al. Ultrasound measurement of gallbladder wall thickening as a diagnositic test and prognostic indicator for severe dengue ine pediatric patients. Pediatr Infect Dis J 2007; 26: 850-2.

46. Srikiatkhachorn A, Krautrachue A, Ratanaprakarn W, et al. Natural history of plasma leakage in dengue hemorrhagic fever: a serial ultrasonographic study. Pediatr Infect Dis J 2007; 26(4): 283-90; discussion 91-2.

47. WHO. Dengue: Guidelines for diagnosis, treatment prevention and control. Geneva: WHO; 2009.

48. Halstead SB. In vivo enhancement of dengue virus infection in rhesus monkeys by passively transferred antibody. J Infect Dis 1979; 140(4): 527-33.

49. Beatty PR, Puerta-Guardo H, Killingbeck SS, Glasner DR, Hopkins K, Harris E. Dengue virus NS1 triggers endothelial permeability and vascular leak that is prevented by NS1 vaccination. Sci Trans/ Med 2015; 7(304): 304ra141.

50. Modhiran N, Watterson D, Muller DA, et al. Dengue virus NS1 protein activates cells via Toll-like receptor 4 and disrupts endothelial cell monolayer integrity. Sci Transl Med 2015; 7(304): 304ra142.

51. Glasner DR, Ratnasiri K, Puerta-Guardo H, Espinosa DA, Beatty PR, Harris E. Dengue virus NS1 cytokine-independent vascular leak is dependent on endothelial glycocalyx components. PLoS Pathog 2017; 13(11): e1006673.

52. Halstead SB. Insights from direct studies on human dengue infections. Proc Natl Acad Sci U S A 2019; 116(1): 17-9.

53. Katzelnick LC, Gresh L, Halloran ME, et al. Antibody-dependent enhancement of severe dengue disease in humans. Science 2017; 358(6365): 929-32.

54. Endy TP, Nisalak A, Chunsuttitwat S, et al. Relationship of preexisting dengue virus (DV) neutralizing antibody levels to viremia and severity of disease in a prospective cohort study of DV infection in Thailand. J Infect Dis 2004; 189(6): 990-1000. 
55. Wilder-Smith A, Ooi EE, Vasudevan SG, Gubler DJ. Update on dengue: epidemiology, virus evolution, antiviral drugs, and vaccine development. Curr Infect Dis Rep 2010; 12(3): 157-64.

56. Rodriguez-Roche R, Sanchez L, Burgher $\mathrm{Y}$, et al. Virus role during intraepidemic increase in dengue disease severity. Vector Borne Zoonotic Dis 2011; 11(6): 675-81.

57. Halstead SB, Nimmannitya S, Cohen SN. Observations related to pathogenesis of dengue hemorrhagic fever. IV. Relation of disease severity to antibody response and virus recovered. Yale J Biol Med 1970; 42(5): 311-28.

58. Gamble J, Bethell D, Day NP, et al. Age-related changes in microvascular permeability: a significant factor in the susceptibility of children to shock? Clin Sci (Lond) 2000; 98(2): 211-6.

59. Khor CC, Chau TN, Pang J, et al. Genome-wide association study identifies susceptibility loci for dengue shock syndrome at MICB and PLCE1. Nature genetics 2011; 43(11): 1139-41.

60. Sierra B, Triska P, Soares P, et al. OSBPL10, RXRA and lipid metabolism confer African-ancestry protection against dengue haemorrhagic fever in admixed Cubans. PLoS Pathog 2017; 13(2): e1006220.

61. Rodriguez-Barraquer I, Costa F, Nascimento EJM, et al. Impact of preexisting dengue immunity on Zika virus emergence in a dengue endemic region. Science 2019; 363(6427): 607-10.

62. Ribeiro GS, Kikuti M, Tauro LB, et al. Does immunity after Zika virus infection cross-protect against dengue? The Lancet Global health 2018; 6(2): e140-e1.

63. Gordon A, Gresh L, Ojeda S, et al. Prior dengue virus infection and risk of Zika: A pediatric cohort in Nicaragua. PLoS Med 2019; 16(1): e1002726.

64. Pedroso C, Fischer C, Feldmann M, et al. Cross-Protection of Dengue Virus Infection against Congenital Zika Syndrome, Northeastern Brazil. Emerg Infect Dis 2019; 25(8).

65. Jentes ES, Lash RR, Johansson MA, et al. Evidence-based risk assessment and communication: a new global dengue-risk map for travellers and clinicians. J Travel Med 2016; 23(6).

66. Wilder-Smith A, Boggild AK. Sentinel Surveillance in Travel Medicine: 20 Years of GeoSentinel Publications (1999-2018). J Travel Med 2018; 25(1).

67. McCarthy AE, Weld LH, Barnett ED, et al. Spectrum of illness in international migrants seen at GeoSentinel clinics in 1997-2009, part 2: migrants resettled internationally and evaluated for specific health concerns. Clinical infectious diseases : an official publication of the Infectious Diseases Society of America 2013; 56(7): 925-33.

68. Leder K, Torresi J, Brownstein JS, et al. Travel-associated illness trends and clusters, 2000-2010. Emerg Infect Dis 2013; 19(7): 1049-73.

69. Olivero RM, Hamer DH, MacLeod WB, et al. Dengue Virus Seroconversion in Travelers to Dengue-Endemic Areas. Am J Trop Med Hyg 2016.

70. Sanchez-Vegas C, Hamer DH, Chen LH, et al. Prevalence of dengue virus infection in US travelers who have lived in or traveled to dengueendemic countries. J Travel Med 2013; 20(6): 352-60.

71. Mohammed HP, Ramos MM, Rivera A, et al. Travel-associated dengue infections in the United States, 1996 to 2005 . Journal of travel medicine 2010; 17(1): 8-14. 
72. Jelinek T. Trends in the epidemiology of dengue fever and their relevance for importation to Europe. Euro Surveill 2009; 14(25).

73. Struchiner CJ, Rocklov J, Wilder-Smith A, Massad E. Increasing Dengue Incidence in Singapore over the Past 40 Years: Population Growth, Climate and Mobility. PLoS One 2015; 10(8): e0136286.

74. Neuberger A, Turgeman A, Lustig Y, Schwartz E. Dengue fever among Israeli expatriates in Delhi, 2015: implications for dengue incidence in Delhi, India. J Travel Med 2016; 23(3).

75. Ferguson RW, Henderson SJ, Lee EA, Jung P. Dengue in Peace Corps Volunteers, 2000-14. J Travel Med 2016; 23(3).

76. Caci JB, Blaylock JM, De La Barrera R, et al. Seroprevalence of Dengue Fever in US Army Special Operations Forces: Initial Results and the Way Ahead. J Spec Oper Med 2014; 14(3): 111-5.

77. Greenaway C, Castelli F. Infectious diseases at different stages of migration: an expert review. J Travel Med 2019; 26(2).

78. Heywood AE, Lopez-Velez R. Reducing infectious disease inequities among migrants. J Travel Med 2019; 26(2).

79. Leder K, Tong S, Weld L, et al. Illness in travelers visiting friends and relatives: a review of the GeoSentinel Surveillance Network. Clin Infect Dis 2006; 43(9): 1185-93.

80. Rodriguez-Morales AJ, Bonilla-Aldana DK, Bonilla-Aldana JC, Mondragon-Cardona A. Arboviral diseases among internally displaced people of Neiva, Colombia, 2015-2017. J Travel Med 2019; 26(2).

81. Wilder-Smith A, Ooi EE, Horstick O, Wills B. Dengue. Lancet 2019; 393(10169): 350-63.

82. Guzman MG, Kouri G, Bravo J, Valdes L, Vazquez S, Halstead SB. Effect of age on outcome of secondary dengue 2 infections. International journal of infectious diseases : IIID : official publication of the International Society for Infectious Diseases 2002; 6(2): 118-24.

83. Hebbal P, Darwich Y, Fong J, Hagmann SHF, Purswani MU. Nephrotic-range proteinuria in an eight-year-old traveler with severe dengue: Case report and review of the literature. Travel Med Infect Dis 2016; 14(1): 45-8.

84. Krishnan N, Purswani M, Hagmann S. Severe dengue virus infection in pediatric travelers visiting friends and relatives after travel to the Caribbean. Am J Trop Med Hyg 2012; 86(3): 474-6.

85. Pang J, Hsu JP, Yeo TW, Leo YS, Lye DC. Diabetes, cardiac disorders and asthma as risk factors for severe organ involvement among adult dengue patients: A matched case-control study. Sci Rep 2017; 7: 39872.

86. Pang J, Salim A, Lee VJ, et al. Diabetes with hypertension as risk factors for adult dengue hemorrhagic fever in a predominantly dengue serotype 2 epidemic: a case control study. PLoS Negl Trop Dis 2012; 6(5): e1641.

87. Yacoub S, Wertheim H, Simmons CP, Screaton G, Wills B. Cardiovascular manifestations of the emerging dengue pandemic. Nat Rev Cardiol 2014; 11(6): 335-45.

88. Bich TD, Pham OK, Hai DH, et al. A pregnant woman with acute cardiorespiratory failure: dengue myocarditis. Lancet 2015; 385(9974):

1260.

89. Hariyanto H, Yahya $\mathrm{CQ}$, Wibowo $\mathrm{P}$, Tampubolon OE. Management of severe dengue hemorrhagic fever and bleeding complications in a primigravida patient: a case report. J Med Case Rep 2016; 10(1): 357.

90. Paixao ES, Costa M, Teixeira MG, et al. Symptomatic dengue infection during pregnancy and the risk of stillbirth in Brazil, 2006-12: a matched case-control study. Lancet Infect Dis 2017; 17(9): 957-64. 
91. Nascimento LB, Siqueira CM, Coelho GE, Siqueira JB, Jr. Symptomatic dengue infection during pregnancy and livebirth outcomes in Brazil, 2007-13: a retrospective observational cohort study. Lancet Infect Dis 2017; 17(9): 949-56.

92. Basurko C, Matheus S, Hilderal H, et al. Estimating the Risk of Vertical Transmission of Dengue: A Prospective Study. Am J Trop Med Hyg 2018.

93. Arragain L, Dupont-Rouzeyrol M, O'Connor O, et al. Vertical Transmission of Dengue Virus in the Peripartum Period and Viral Kinetics in Newborns and Breast Milk: New Data. J Pediatric Infect Dis Soc 2017; 6(4): 324-31.

94. Wilder-Smith A, Leong WY. Risk of severe dengue is higher in patients with sickle cell disease: a scoping review. J Travel Med 2019; 26(1).

95. Leder K, Steffen R, Cramer JP, Greenaway C. Risk assessment in travel medicine: how to obtain, interpret, and use risk data for informing pre-travel advice. J Travel Med 2015; 22(1): 13-20.

96. Wichmann O, Gascon J, Schunk M, et al. Severe dengue virus infection in travelers: risk factors and laboratory indicators. J Infect Dis 2007; 195(8): 1089-96.

97. Meltzer E, Heyman Z, Bin H, Schwartz E. Capillary leakage in travelers with dengue infection: implications for pathogenesis. Am J Trop Med Hyg 2012; 86(3): 536-9.

98. Stanaway JD, Shepard DS, Undurraga EA, et al. The global burden of dengue: an analysis from the Global Burden of Disease Study 2013. Lancet Infect Dis 2016; 16(6): 712-23.

99. Wilder-Smith A, Byass P. The elusive global burden of dengue. Lancet Infect Dis 2016; 16(6): 629-31.

100. Schmidt-Chanasit J, Tenner-Racz K, Poppert D, et al. Fatal dengue hemorrhagic fever imported into Germany. Infection 2012; 40(4): 4413.

101. Jensenius M, Berild D, Ormaasen V, Maehlen J, Lindegren G, Falk KI. Fatal subarachnoidal haemorrhage in a Norwegian traveller with dengue virus infection. Scand J Infect Dis 2007; 39(3): 272-4.

102. Janssen HL, Bienfait HP, Jansen CL, et al. Fatal cerebral oedema associated with primary dengue infection. J Infect 1998; 36(3): 344-6. 103. Jensenius M, Han PV, Schlagenhauf $P$, et al. Acute and potentially life-threatening tropical diseases in western travelers--a GeoSentinel multicenter study, 1996-2011. The American Journal of Tropical Medicine and Hygiene 2013; 88(2): 397-404.

104. Batchelor T. Timing of administration of dengue vaccine in travellers with a recent confirmed dengue infection. J Travel Med 2018; 25(1). 105. Kouri GP, Guzman MG, Bravo JR. Why dengue haemorrhagic fever in Cuba? 2. An integral analysis. Trans R Soc Trop Med Hyg 1987;

81(5): 821-3.

106. Guzman MG, Kouri G, Valdes L, et al. Epidemiologic studies on Dengue in Santiago de Cuba, 1997. Am J Epidemio/ 2000; 152(9): 793-9; discussion 804.

107. Anderson KB, Chunsuttiwat S, Nisalak A, et al. Burden of symptomatic dengue infection in children at primary school in Thailand: a prospective study. Lancet 2007; 369(9571): 1452-9.

108. Gibbons RV, Kalanarooj S, Jarman RG, et al. Analysis of Repeat Hospital Admissions for Dengue to Estimate the Frequency of Third or Fourth Dengue Infections Resulting in Admissions and Dengue Hemorrhagic Fever, and Serotype Sequences. Am J Trop Med Hyg 2007; 77(5): 910-3. 
109. Clapham HE, Cummings DAT, Johansson MA. Immune status alters the probability of apparent illness due to dengue virus infection: Evidence from a pooled analysis across multiple cohort and cluster studies. PLoS Neg/ Trop Dis 2017; 11(9): e0005926.

110. Montoya M, Gresh L, Mercado JC, et al. Symptomatic versus inapparent outcome in repeat dengue virus infections is influenced by the time interval between infections and study year. PLoS Negl Trop Dis 2013; 7(8): e2357.

111. Endy TP, Yoon IK, Mammen MP. Prospective cohort studies of dengue viral transmission and severity of disease. Curr Top Microbiol Immunol 2010; 338: 1-13.

112. Rothman AL, Medin CL, Friberg H, Currier JR. Immunopathogenesis Versus Protection in Dengue Virus Infections. Current tropical medicine reports $2014 ; \mathbf{1}(1)$ : $13-20$.

113. Sridhar S, Luedtke A, Langevin E, et al. Effect of Dengue Serostatus on Dengue Vaccine Safety and Efficacy. N Eng/ J Med 2018.

114. Salje H, Cummings DAT, Rodriguez-Barraquer I, et al. Reconstruction of antibody dynamics and infection histories to evaluate dengue risk. Nature 2018; 557(7707): 719-23.

115. Katzelnick LC, Harris E, Participants in the Summit on Dengue Immune Correlates of P. Immune correlates of protection for dengue: State of the art and research agenda. Vaccine 2017; 35(36): 4659-69.

116. Dengue vaccine: WHO position paper-September 2018. Weekly Epidemiological Record 2018; 93 457-76.

117. Burke DS, Nisalak A, Johnson DE, Scott RM. A prospective study of dengue infections in Bangkok. Am J Trop Med Hyg 1988; 38(1): 172-

80.

118. Graham RR, Juffrie M, Tan R, et al. A prospective seroepidemiologic study on dengue in children four to nine years of age in Yogyakarta, Indonesia I. studies in 1995-1996. Am J Trop Med Hyg 1999; 61(3): 412-9.

119. Thein S, Aung MM, Shwe TN, et al. Risk factors in dengue shock syndrome. Am J Trop Med Hyg 1997; 56(5): 566-72.

120. Olkowski S, Forshey BM, Morrison AC, et al. Reduced risk of disease during postsecondary dengue virus infections. J Infect Dis 2013; 208(6): 1026-33.

121. Lalani T, Yun H, Tribble D, et al. A comparison of compliance rates with anti-vectorial protective measures during travel to regions with dengue or chikungunya activity, and regions endemic for Plasmodium falciparum malaria. J Travel Med 2016; 23(5).

122. Goodyer L, Schofield S. Mosquito repellents for the traveller: does picaridin provide longer protection than DEET? J Travel Med 2018; 25(suppl_1): S10-S5.

123. Wilder-Smith A. Dengue vaccines for travelers: has the time come? J Travel Med 2015; 22(3): 200-2.

124. Wilder-Smith A. Serostatus-dependent performance of the first licensed dengue vaccine: implications for travellers. $J$ Travel Med 2018;

25(1).

125. Loconsole D, Metallo A, De Robertis AL, Morea A, Quarto M, Chironna M. Seroprevalence of Dengue Virus, West Nile Virus, Chikungunya Virus, and Zika Virus in International Travelers Attending a Travel and Migration Center in 2015-2017, Southern Italy. Vector Borne Zoonotic Dis 2018; 18(6): 331-4.

126. Ratnam I, Black J, Leder K, et al. Incidence and seroprevalence of dengue virus infections in Australian travellers to Asia. Eur J Clin Microbiol Infect Dis 2012; 31(6): 1203-10.

127. Arien KK, Wilder-Smith A. Dengue vaccine: reliably determining previous exposure. The Lancet Global health 2018. 
128. Durbin AP, Gubler DJ. What is the prospect of a safe and effective dengue vaccine for travelers? J Travel Med 2019.

129. Tang KF, Ooi EE. Diagnosis of dengue: an update. Expert Rev Anti Infect Ther 2012; 10(8): 895-907.

130. Chaterji S, Allen JC, Jr., Chow A, Leo YS, Ooi EE. Evaluation of the NS1 rapid test and the WHO dengue classification schemes for use as bedside diagnosis of acute dengue fever in adults. Am J Trop Med Hyg 2011; 84(2): 224-8.

131. Luo R, Fongwen N, Kelly-Cirino C, Harris E, Wilder-Smith A, Peeling R. Rapid diagnostic tests for determining dengue serostatus: a systematic review and key informant interviews. Clin Microbiol Infect 2019.

132. Ang LW, Thein TL, Ng Y, et al. A 15-year review of dengue hospitalizations in Singapore: Reducing admissions without adverse consequences, 2003 to 2017. PLoS Negl Trop Dis 2019; 13(5): e0007389.

133. Dengue: guidelines for diagnosis, treatment, prevention and control. Geneva: World Health Organization; 2009.

134. Lam PK, Tam DT, Diet TV, et al. Clinical characteristics of Dengue shock syndrome in Vietnamese children: a 10-year prospective study in a single hospital. Clin Infect Dis 2013; 57(11): 1577-86.

135. Statler J, Mammen M, Lyons A, Sun W. Sonographic findings of healthy volunteers infected with dengue virus. J Clin Ultrasound 2008;

36(7): 413-7.

136. Ling LM, Wilder-Smith A, Leo YS. Fulminant hepatitis in dengue haemorrhagic fever. Journal of clinical virology : the official publication of the Pan American Society for Clinical Virology 2007; 38(3): 265-8.

137. TDR W. Dengue guidelines for diagnosis, treatment, prevention and control: new edition. 2009.

http://www.wpro.who.int/mvp/documents/handbook_for_clinical_management_of_dengue.pdf.

138. Lye DC, Archuleta S, Syed-Omar SF, et al. Prophylactic platelet transfusion plus supportive care versus supportive care alone in adults with dengue and thrombocytopenia: a multicentre, open-label, randomised, superiority trial. Lancet 2017; 389(10079): 1611-8.

139. Lee IK, Huang CH, Huang WC, et al. Prognostic Factors in Adult Patients with Dengue: Developing Risk Scoring Models and Emphasizing

Factors Associated with Death </=7 Days after Illness Onset and </=3 Days after Presentation. J Clin Med 2018; 7(11).

140. Seet RC, Quek AM, Lim EC. Post-infectious fatigue syndrome in dengue infection. J Clin Virol 2007; 38(1): 1-6.

141. Zea D, Foley K, Carey J. Myocarditis in a traveler returning from the Dominican Republic: an unusual presentation of dengue fever. Am J

Trop Med Hyg 2014; 91(1): 156-8.

142. Kirawittaya T, Yoon IK, Wichit S, et al. Evaluation of Cardiac Involvement in Children with Dengue by Serial Echocardiographic Studies. PLoS Negl Trop Dis 2015; 9(7): e0003943.

143. Ling LM, Wilder-Smith A, Leo YS. Fulminant hepatitis in dengue haemorrhagic fever. J Clin Virol 2007; 38(3): 265-8.

144. Carod-Artal FJ, Wichmann O, Farrar J, Gascon J. Neurological complications of dengue virus infection. The Lancet Neurology 2013; 12(9): 906-19.

145. Tang X, Zhao S, Chiu APY, Wang X, Yang L, He D. Analysing increasing trends of Guillain-Barre Syndrome (GBS) and dengue cases in Hong Kong using meteorological data. PLoS One 2017; 12(12): e0187830.

146. Boo YL, Aris MAM, Chin PW, Sulaiman WAW, Basri H, Hoo FK. Guillain-Barre syndrome complicating dengue fever: Two case reports. Ci Ji Yi Xue Za Zhi 2016; 28(4): 157-9. 
147. Kobayashi K, Hikone M, Sakamoto N, et al. Dengue-associated hemophagocytic syndrome in a Japanese traveler: a case report. J Travel Med 2015; 22(1): 64-6.

148. Verma R, Sahu R, Holla V. Neurological manifestations of dengue infection: a review. J Neurol Sci 2014; 346(1-2): 26-34.

149. Kumar J, Kumar A, Gupta S, Jain D. Dengue haemorrhagic fever: an unusual cause of intracranial haemorrhage. BMJ Case Rep 2009; 2009: bcr2006100909.

150. Dalugama C, Shelton J, Ekanayake M, Gawarammana IB. Dengue fever complicated with Guillain-Barre syndrome: a case report and review of the literature. J Med Case Rep 2018; 12(1): 137.

151. Vieira M, Cruz ACR, Barros ANM, et al. Guillain-Barre syndrome and dengue-like disease in 2015: temporal relationship in Piaui state and implications on Zika virus surveillance. Rev Inst Med Trop Sao Paulo 2017; 59: e22.

152. Fragoso YD, Gomes S, Brooks JB, et al. Guillain-Barre syndrome and dengue fever: report on ten new cases in Brazil. Arq Neuropsiquiatr 2016; 74(12): 1039-40.

153. Simon O, Billot S, Guyon D, et al. Early Guillain-Barre Syndrome associated with acute dengue fever. J Clin Virol 2016; 77: 29-31.

154. Ralapanawa DM, Kularatne SA, Jayalath WA. Guillain-Barre syndrome following dengue fever and literature review. BMC Res Notes 2015; 8: 729.

155. Shivanthan MC, Ratnayake EC, Wijesiriwardena BC, Somaratna KC, Gamagedara LK. Paralytic squint due to abducens nerve palsy: a rare consequence of dengue fever. BMC Infect Dis 2012; 12: 156.

156. Lim M, Goh HK. Rhabdomyolysis following dengue virus infection. Singapore Med J 2005; 46(11): 645-6.

157. Ramos JM, Tello A, Alzamora A, Ramon ML. Optic neuritis in a traveler returning from Dominican Republic to Spain with dengue virus infection. J Travel Med 2015; 22(2): 133-5.

158. Thein TL, Lye DC, Leo YS, Wong JG, Hao Y, Wilder-Smith A. Severe neutropenia in dengue patients: prevalence and significance. Am J Trop Med Hyg 2014; 90(6): 984-7. 